\title{
Determination of Fungicide Resistance in Botrytis cinerea from Strawberry in the Central Coast Region of California
}

\begin{abstract}
Andrew Pokorny, Department of Plant Science, California State University, Fresno 93740; Joseph Smilanick and Chang-Lin Xiao, United States Department of Agriculture, Agricultural Research Service, San Joaquin Valley Agricultural Sciences Center, Parlier, CA 93648; James J. Farrar, University of California Statewide Integrated Pest Management Program, Davis 95618; and Anil Shrestha, Department of Plant Science, California State University, Fresno 93740
\end{abstract}

Accepted for publication 19 February 2016. Published 2 March 2016.

\section{ABSTRACT}

Pokorny, A., Smilanick, J., Xiao, C.-L., Farrar, J. J., and Shrestha, A. 2016. Determination of fungicide resistance in Botrytis cinerea from strawberry in the Central Coast region of California. Plant Health Prog. 17:30-34.

Grey mold, caused by Botryis cinerea, is one of the most important diseases of strawberry in California. Management of grey mold typically relies on repeated fungicide applications. The occurrence of fungicide resistance in $B$. cinerea was examined in the Central Coast strawberry production region of California. In mid-May 2013, 59 samples consisting of a single diseased fruit or plant part with gray mold symptoms were collected from six different strawberry fields. Single hyphal tip cultures were then used for mycelial growth assays to compare sensitivities to four different fungicides-boscalid, fenhexamid, iprodione, and pyraclostrobin. Each isolate was tested against discriminatory doses of each of the fungicides. In addition, representative highly sensitive and highly resistant isolates were tested against a range of fungicide concentrations to determine $\mathrm{EC}_{50}$ values. Although all of the 59 isolates were sensitive to iprodione, $37 \%, 31 \%$, and $29 \%$ of the isolates were resistant to pyraclostrobin, fenhexamid, and boscalid, respectively. In some instances the isolates were dual and triple-resistant to these fungicides. $\mathrm{EC}_{50}$ values were often higher than $100 \mathrm{mg} / \mathrm{liter}$, which was the highest concentration used. Therefore, appropriate fungicide resistance management measures should be employed in strawberry growing areas of the Central Coast region of California.

\section{INTRODUCTION}

Strawberry (Fragaria $\times$ ananassa Duch.) is one of the most important fruit crops in the United States, with an estimated total value of $>\$ 2.8$ billion from a total of 23,800 ha in 2014 (USDANASS 2014). California is the largest strawberry producing state, accounting for $85 \%$ of the total production and $65 \%$ of the area under strawberry cultivation (USDA-NASS 2014; CDFA 2014). Within California, the Central Coast region is one of the main strawberry production areas (Strand 2008).

Gray mold of strawberries, caused by Botrytis cinerea, is a particularly destructive disease that causes considerable losses of the crop. In terms of economic impact, gray mold is ranked as the most important strawberry disease. If left unchecked, under ideal environmental conditions, substantial losses can occur before and after harvest (Maas 1998). Gray mold management practices include plastic mulch, field sanitation, cultural practices to prevent fruit wetness and promote rapid drying of foliage, weather monitoring, and fungicide applications (Mertely et al. 2000; UC IPM 2008). In many areas, routine fungicide applications are a common method of managing this disease in strawberries (Cooley et al. 1996).

Fungicides from a number of different mode-of-action groups are used for management of gray mold of strawberry. The University of California's Statewide Integrated Pest Management Program recommends seven commercially available fungicides with nine different modes-of-action for gray mold on strawberries

Corresponding author: Anil Shrestha. Email: ashrestha@csufresno.edu.

doi:10.1094/PHP-RS-15-0053

(C) 2016 The American Phytopathological Society in California (UC IPM 2008). The causal agent of gray mold, $B$. cinerea, is considered a high-risk for development of fungicide resistance because of its short life cycle and prolific asexual reproduction, which allows for the rapid expression of target site mutations within the pathogen (Kim and Xiao 2011; FRAC 2013). Botrytis cinerea isolates have been reported with resistance to benzimidazoles, diacarboximides, anilinopyryimidines, hydroxyanilides, and quinone outside inhibitors (Veloukas et al. 2011). A recent study on the control of gray mold on table grapes after harvest during cold storage in California discovered that the fungicide sensitivity of the $B$. cinerea isolates collected in numerous vineyards was reduced to at least one of the seven fungicides tested, with the exception of fenhexamid, where reduced sensitivity was not found (Smilanick et al. 2010).

The management of fungicide resistance in $B$. cinerea is a major challenge in control of gray mold of strawberry (Bardas et al. 2010; Baroffio et al. 2003). Fungicides are the most used inseason pesticide by weight in strawberry production in California (CDPR 2014), resulting in heavy fungicide resistance selection pressure on the fungus. Fungicide resistance in $B$. cinerea from strawberries is an increasingly important problem (FernandezOrtuno et al. 2014; Weber 2011). If the rate at which new fungicides with novel modes of action are introduced is slower than the rate of occurrence of resistance in $B$. cinerea, then it will be difficult for growers to continue to effectively manage gray mold of strawberries. Therefore, the objective of this study was to determine the occurrence of resistance to several commercially available fungicide active ingredients in $B$. cinerea on strawberries produced in California's Central Coast region. In this study, 59 B. cinerea isolates were screened against boscalid, fenhexamid, iprodione, and pyraclostrobin to determine the relative sensitivity of each isolate to each active ingredient. One 
of the fungicides tested included a combination of boscalid and pyraclostrobin (Pristine $20 \mathrm{WG}$ ). These active ingredients were selected to represent components of a typical fungicide spray program in strawberries in California.

\section{ISOLATE COLLECTION}

Botrytis cinerea samples were collected randomly from strawberry fields in Monterey County, California (Fig. 1). Each sample was a single gray mold-diseased fruit or plant part. Samples were collected from six geographically different field locations. Within a single location, random samples were taken to represent within-field population variation. Each sample was collected by rubbing a sterile cotton swab against a sporulating lesion (Fig. 2). The tip of the swab was broken off, sealed in a plastic tube, and transported to the lab. Isolation was conducted under a laminar-flow hood to reduce the chance of contamination. Swab tips were lightly brushed on a petri dish containing potato dextrose agar (PDA) plus $200 \mathrm{mg} /$ liter penicillin and $200 \mathrm{mg} / \mathrm{liter}$ streptomycin sulfate. Petri dishes were incubated at $16^{\circ} \mathrm{C}$ under fluorescent lights for 24 to $48 \mathrm{~h}$ until mycelial growth was observed. Plugs were taken from the outer edges of the mycelial growth and transferred onto new PDA (without antibiotics) petri dishes. This process was repeated until a culture was obtained that was free of contamination. For each isolate, a single hyphal tip was excised under a dissecting microscope and transferred to PDA for production of a single genotype pure culture. Isolates not tested immediately were stored in a refrigerator at $6^{\circ} \mathrm{C}$ for no more than two weeks before use. A total of 59 isolates were collected from six different sampling locations. Twenty-two isolates were collected from a site north of Gonzalez, nine isolates from a site west of Gonzalez, eight isolates from a site southwest of Gonzalez, seven isolates from a site west of Soledad, ten isolates from site southwest of Soledad, and three isolates from a site south of Chualar.

\section{FUNGICIDE SENSITIVITY TESTING}

Two types of media were utilized in the fungicide resistance assays. One-percent malt extract agar was used for the nonamended control, fenhexamid, iprodione, and pyraclostrobin assays, and $0.5 \%$ yeast extract agar was used for the non-amended control and boscalid assay in order to avoid interference of sugars with the assay (Weber and Hahn 2011). In addition, for the pyraclostrobin assays, salicylic hydroxamic acid (SHAM) was added to the malt extract agar at $100 \mathrm{mg} / \mathrm{liter}$ in order to inhibit the alternative oxidase respiration pathway (Olaya and Köller 1999; Kim and Xiao 2010; Kinay et al. 2007). Agars were prepared and autoclaved according to the manufacturer's instructions. Commercial fungicides were used to prepare fungicide-amended media. Cabrio EG (pyraclostrobin) and Endura (boscalid) were the sources of the two active ingredients in the combination product Pristine 20WG. Elevate 50WG was the source of fenhexamid and Rovral 48SC was the source of iprodione. Fungicides and SHAM were prepared as stock solutions and were added after autoclaving to the cooling agar (Brent and Hollomon 2007). The fungicide active ingredients were suspended in various agars at two discriminatory concentrations chosen from the studies of Weber and Hahn (2011). The treatments included non-amended control, $1 \mathrm{mg} / \mathrm{liter}$ boscalid, $50 \mathrm{mg} / \mathrm{liter}$ boscalid, $1 \mathrm{mg} /$ liter fenhexamid, $50 \mathrm{mg} / \mathrm{liter}$ fenhexamid, $5 \mathrm{mg} / \mathrm{liter}$ iprodione, $50 \mathrm{mg} / \mathrm{liter}$ iprodione, 0.1 $\mathrm{mg} /$ liter pyraclostrobin + SHAM, and $10 \mathrm{mg} /$ liter pyraclostrobin + SHAM.

A single 0.16-inch (4-mm) plug taken from the outer edges of a 7-day-old culture was placed upside down on the surface of the media. Radial mycelial growth was measured with a digital caliper after $48 \mathrm{~h}$ of growth at $20^{\circ} \mathrm{C}$ in the dark. These measurements were converted to the percent relative growth, which was calculated by dividing the diameter of the colony of each isolate on fungicide-amended agar by that of the nonamended control, then multiplying by 100 (Cox et al. 2009). Relative growth was assessed for four single-colony replicates per isolate. Isolates were divided into four sensitivity categories by the following guidelines: isolates with relative growth values $<50 \%$ for both the low and high rate were categorized as "highly sensitive"; isolates whose relative growths were $>50 \%$ at the low rate but $<50 \%$ at the high rate were deemed as "moderately sensitive"; isolates with relative growth $>50 \%$ for both the low and high rates but still exhibiting an evident dose response were categorized as "moderately resistant"; isolates with relative growth $>50 \%$ for both the low and high rate and with little or no observable dose response were categorized as "highly resistant."

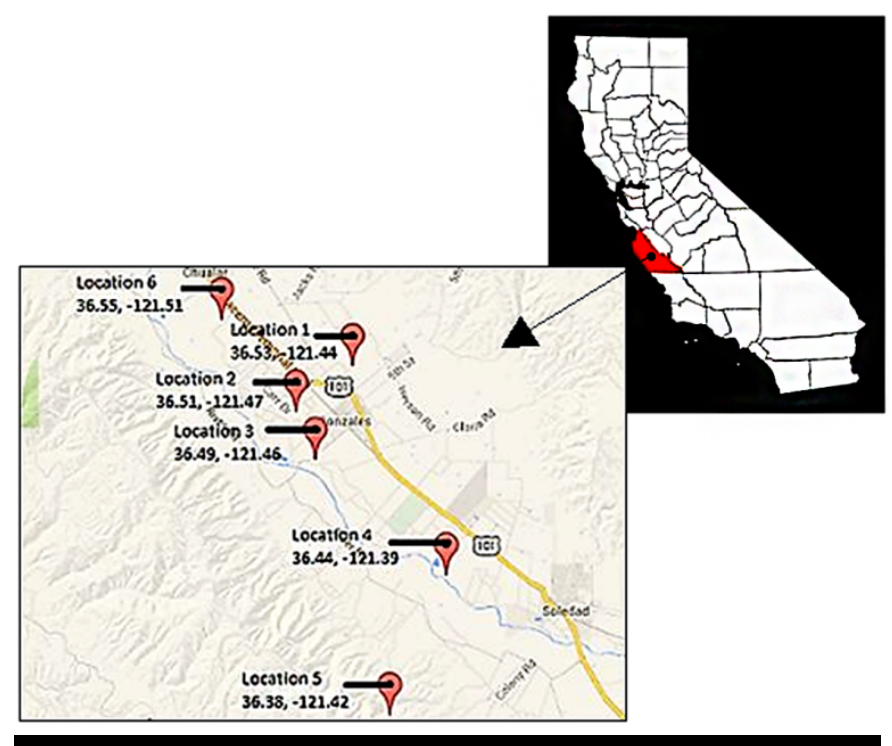

FIGURE 1

Map of California counties with Monterey County shaded red and the inset indicating the specific sampling locations.

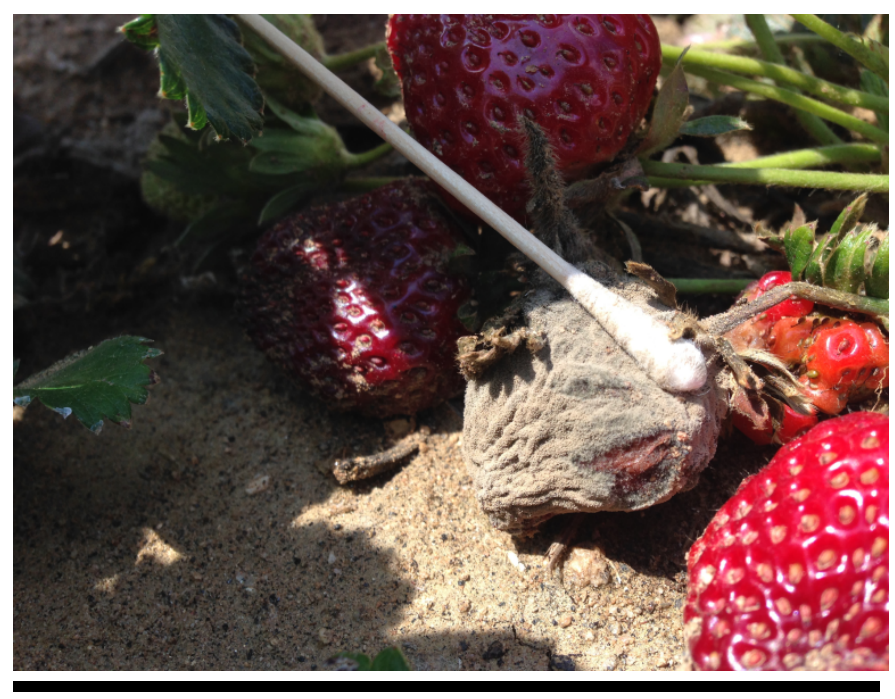

FIGURE 2

Sampling of sporulating lesions on a strawberry infected with Botrytis cinerea. 
Of those isolates screened, 28 isolates were sensitive to all four of the active ingredients included in the study. All isolates were sensitive to iprodione. Of the 59 isolates screened, $37 \%$ (22) exhibited reduced sensitivity to pyraclostrobin, $31 \%$ (18) exhibited reduced sensitivity to fenhexamid, and 29\% (17) exhibited reduced sensitivity to boscalid (Table 1).

$\begin{array}{lcccc}\text { TABLE 1 } & \text { Classification of isolates collected from the 59 locations } \\ \text { and their sensitivity to the various fungicides tested. }\end{array}$

Twelve isolates were found with resistance to a single active ingredient, with seven isolates resistant to only pyraclostrobin, three resistant to only fenhexamid, and two resistant to only boscalid. Twelve isolates were discovered with resistance to two active ingredients, with four isolates resistant to boscalid and fenhexamid, four resistant to boscalid and pyraclostrobin, and four resistant to fenhexamid and pyraclostrobin. Seven isolates were observed with triple resistance to boscalid, fenhexamid, and pyraclostrobin.

Fungicide-resistant isolates were discovered from all sampling locations (data not shown). There were not enough isolates from each location to analyze fungicide resistance profiles by location.

While resistance was found frequently in this study it is interesting to note that all isolates exhibited sensitivity to iprodione. This was unexpected because iprodione has been registered for use in strawberry for a number of years and is classified as a medium to high resistance risk compound (FRAC 2015). In addition, the first confirmed cases of fungicide resistance were reported in 1979 in the dicarboximides, the fungicide class of iprodione (Eckert 1988). The wide distribution of dicarboximide resistant isolates has greatly reduced the usefulness of these compounds in controlling gray mold in many countries (Ma and Michailides 2005; Leroux et al. 2002). Label restrictions allowing for only a single iprodione application before the first bloom in strawberries and the relative concern over the effectiveness of dicarboximides as a whole may have led to a significant decrease in iprodione use for strawberry gray mold in California.

Boscalid and pyraclostrobin are applied together in strawberries as a two-active-ingredient, pre-mixed product called Pristine. Four of the 59 isolates in the study were resistant to both boscalid and pyraclostrobin, while seven isolates were resistant to boscalid, pyraclostrobin, and fenhexamid. This suggests the value of pre-mixed products in retarding the emergence and proliferation of fungicide resistant isolates should be investigated. Label restrictions allow the application of Pristine for control of gray mold five times in a growing season with no more than two sequential applications without switching to a different fungicidal active ingredient. Pristine is used extensively during the prolonged strawberry season in the Central Coast region (CDPR 2014; Steven T. Koike, University of California Cooperative Extension-Monterey County, 2013, personal communication). The level of fenhexamid resistance identified in this study is similar to previous studies (Weber 2011; Grabke et al. 2013).

\section{EC $_{50}$ DETERMINATION}

$\mathrm{EC}_{50}$ is the effective concentration of fungicide necessary to reduce mycelial growth by $50 \%$ in comparison to growth in the absence of fungicide. For this experiment, two representative isolates from both the "highly resistant" and "highly sensitive" categories for bosacalid, fenhexamid, and pyraclostrobin, and two representative isolates from the "highly sensitive" category for iprodione were selected for further screening. These isolates were screened against a wider range of fungicide rates ( 0.01 to 100 $\mathrm{mg} / \mathrm{liter}$ ) in order to get a more detailed response of each isolate to a respective fungicide active ingredient. The methodology used was similar to first experiment with the only difference being the number of concentrations (treatments) used. The concentrations included a non-amended control, 0.01, 0.1, 1.0, 10.0, and 100.0 $\mathrm{mg} /$ liter of boscalid, fenhexamid, and iprodione, respectively, and $0.01,0.1,1.0,10.0$, and $100.0 \mathrm{mg} /$ liter of pyraclostrobin + SHAM. These additional treatments allowed for the development of detailed dose response curves. The average $\mathrm{EC}_{50}$ values were determined using a sigmoidal, logistic, 3 parameter non-linear regression in Sigma Plot 12.3 for each fungal isolate and fungicide active ingredient combination. The equation was as follows:

$$
y=\frac{a}{1+\left(\frac{x}{x 0}\right)^{b}}
$$

Where the coefficients $a$ and $b$ are the model parameters that were fitted, $x$ is the concentration required to control $50 \%$ of the population, and $y$ is equivalent to $50 \%$ relative growth. The $\mathrm{EC}_{50}$ was estimated by solving for $x$ with the given parameters.

The experiment was arranged as a completely randomized design where each petri dish was randomly distributed in an incubation room. Four replicates per isolate per active ingredient concentration were used. The average $\mathrm{EC}_{50}$ values were generated from dose response curves by utilizing a sigmoidal, logistic, three-parameter, non-linear regression in Sigma Plot 12.3 for each selected fungal isolate and fungicide active ingredient combination.

The isolates showed differences in responses (percent relative growth) to boscalid, fenhexamid, and pyraclostrobin but not to iprodione. Based on these responses the $\mathrm{EC}_{50}$ values showed a distinct difference between the sensitive and resistant isolates for boscalid, fenhexamid, and pyraclostrobin. The $\mathrm{EC}_{50}$ values for isolates sensitive to boscalid were 0.13 and $0.29 \mathrm{mg} / \mathrm{liter}$, whereas $\mathrm{EC}_{50}$ values for isolates resistant to boscalid were greater than the highest concentration tested ( $>100 \mathrm{mg} / \mathrm{liter})$. The $\mathrm{EC}_{50}$ values for isolates sensitive to fenhexamid were 0.81 and $1.51 \mathrm{mg} / \mathrm{liter}$, whereas the estimated $\mathrm{EC}_{50}$ values for isolates resistant to fenhexamid were $36.3 \mathrm{mg} /$ liter and greater than the highest concentration tested (>100 mg/liter). The $\mathrm{EC}_{50}$ values calculated for the isolate sensitive to pyraclostrobin were 0.32 and 1.63 $\mathrm{mg} /$ liter, whereas the $\mathrm{EC}_{50}$ for the isolates resistant to pyraclostrobin were greater than the highest concentration tested ( $>100 \mathrm{mg} / \mathrm{liter}$ ). As mentioned earlier, none of the isolates showed resistance to iprodione and the $\mathrm{EC}_{50}$ values of the sensitive isolates were 0.36 and $1.41 \mathrm{mg} / \mathrm{liter}$.

\section{CONCLUSIONS}

Although this study had a relatively small sample, $37 \%$ of isolates were highly or moderately resistant to pyraclostrobin, $31 \%$ were highly or moderately resistant to fenhexamid, and $29 \%$ were highly or moderately resistant to boscalid. In addition, $37 \%$ 
of isolates were resistant to two fungicides and $12 \%$ were resistant to three fungicides. Forster and Staub (1996) estimated that a $25 \%$ share of highly or moderately resistant isolates in a field population could be sufficient to significantly decrease the efficacy of a fungicide and this proportion could very likely be less. Control of gray mold in California's Central Coast strawberry producing region is difficult because of the documented resistance to multiple chemical classes of fungicides. In addition, managing fungicide resistance in $B$. cinerea is difficult due to its vast host range, prolific reproduction, and the rapid expression of resistant biotypes within a population (Kim and Xiao 2011).

The fungicide rotation guidelines that are incorporated into label use restrictions by the fungicide manufacturers and pesticide regulatory agencies are designed to limit the occurrence of resistance and manage residue levels. These guidelines are developed by investigating baseline responses of a pathogen to a new chemical class before the introduction of that class to the market, and by evaluating and screening for resistance after a product has been released (Beresford 1994; Russell 2002). For instance, specific labeling may allow a grower to use a product five times in a season but not make more than two consecutive applications before switching to a fungicide with a different mode of action. These types of guidelines are typical of fungicides that have been classified as having a medium to low risk of resistance development. Other classes of fungicides that have previously been described as having a high risk of the development of resistance are sometimes limited to only one application during a growing season (Brent and Hollomon 1995).

The keys to managing fungicide resistance are prevention through integrated pest management, rotation of modes of action, and adjustment of fungicide programs supported by rapid detection of isolates exhibiting decreasing sensitivity to fungicides (Weber and Hahn 2011). Many growers have implemented integrated pest management (IPM) programs with intensive scouting and non-chemical control methods (UC IPM 2008). While these practices contribute to control, strawberry growers still often need to utilize chemical fungicides to protect their investment (Sorensen et al. 1997). Although continued adherence to fungicide resistance management guidelines and fungicide label requirements is necessary, identification and development of additional effective practices is required to maintain current strawberry production levels in the Central Coast region of California.

\section{DISCLAIMER}

Mention of trade names or commercial products in this article is solely for the purpose of providing specific information and does not imply recommendations or endorsement by the U.S. Department of Agriculture. USDA is an equal opportunity provider and employer.

\section{LITERATURE CITED}

Bardas, G. A., Veloukas, T., Koutita, O., and Karaoglanidis, G. S. 2010. Multiple resistance of Botrytis cinerea from kiwifruit to SDHIs, QoIs and fungicides of other chemical groups. Pest Manag. Sci. 66:967-973.

Baroffio, C. A., Siegfried, W., and Hilber, U. W. 2003. Long-term monitoring for resistance of Botryotinia fuckeliana to anilinopyrimidine, phenylpyrrole, and hydroxyanilide fungicides in Switzerland. Plant Dis. 87:662-666.

Brent, K. J., and Hollomon, D. W. 1995. Pages 7-27 in: Fungicide resistance in crop pathogens: How can it be managed? FRAC Monograph No. 1, Crop Life Int., Brussels, Belgium.
Brent, K. J., and Hollomon, D. W. 2007. Pages 5-42 in: Fungicide resistance: The assessment of risk. FRAC Monograph No. 2, Crop Life Int., Brussels, Belgium.

Beresford, R. 1994. Understanding fungicide resistance. The Orchardist $67: 24$.

CDFA. 2014. California agricultural statistics 2013 crop year. California Dept. of Food and Agric., Sacramento, CA. Online: https://www.cdfa.ca.gov /Statistics/PDFs/CropYearStats2013 NASS.pdf

CDPR 2014. Summary of pesticide use report 2012. California Dept. of Pesticide Regulation., Sacramento, CA. Online: http://www.cdpr.ca.gov /docs/pur/pur12rep/chmrpt12.pdf

Cooley, D. R., Wilcox, W. F., Kovach, J., and Schloemann, S. G. 1996. Integrated pest management programs for strawberries in the northeastern United States. Plant Dis. 80:228-237.

Cox, K. D., Quello, K., Deford, R. J., and Beckerman, J. L. 2009. A rapid method to quantify fungicide sensitivity in the brown rot pathogen Monilinia fructicola. Plant Dis. 93:328-331.

Eckert, J. W. 1988. Historical development of fungicide resistance in plant pathogens. Pages 1-3 in: Fungicide Resistance in North America. C. J. Delp, ed. American Phytopathological Society, St. Paul, MN.

Fernández-Ortuño, D., Grabke, A., Li, X., and Schnabel, G. 2014. Independent emergence of resistance to seven chemical classes of fungicides in Botrytis cinerea. Phytopathology 105:424-432.

Forster, B., and Staub, T. 1996. Basis for use strategies of anilinopyrimidine and phenylpyrrole fungicides against Botrytis cinerea. Crop Prot. 15:529537.

FRAC 2013. Pathogen risk list 2013. Fungicide Resistance Action Committee, CropLife Int., Brussels, Belgium. Online: http://www.frac.info/docs /default-source/publications/pathogen-risk/pathogen-risk-list.pdf

FRAC 2015. FRAC code list 2015. Fungicide Resistance Action Committee, CropLife Int., Brussels, Belgium. Online: http://www.frac.info/docs /default-source/publications/frac-code-list/frac-code-list-2015finalC2AD7AA36764.pdf

Grabke, A., Fernández-Ortuño, D., and Schnabel, G. 2013. Fenhexamid resistance in Botrytis cinerea from strawberry fields in the Carolinas is associated with four target gene mutations. Plant Dis. 97:271-276.

Kinay, P., Mansour, M. F., Mlikota Gabler, F., Margosan, D. A., and Smilanick, J. L. 2007. Characterization of fungicide-resistant isolates of Penicillium digitatum collected in California. Crop Prot. 26:647-656.

Kim, Y. K., and Xiao, C. L. 2010. Resistance to pyraclostrobin and boscalid in populations of Botrytis cinerea from stored apples in Washington State. Plant Dis. 94:604-612.

Kim, Y. K., and Xiao, C. L. 2011. Stability and fitness of pyraclostrobin-and boscalid-resistant phenotypes in field isolates of Botrytis cinerea from apple. Phytopathology 101:1385-1391.

Leroux, P., Fritz, R., Debieu, D., Albertini, C., Lanen, C., Bach, J., and Chapeland, F. 2002. Mechanisms of resistance to fungicides in field strains of Botrytis cinerea. Pest Manag. Sci. 58:876-888.

Ma, Z., and Michailides, T. J. 2005. Advances in understanding molecular mechanisms of fungicide resistance and molecular detection of resistant genotypes in phytopathogenic fungi. Crop Prot. 24:853-863.

Maas, J. L., ed. 1998. Compendium of Strawberry Diseases, 2nd Ed. American Phytopathological Society, St. Paul, MN.

Mertely, J. C., Chandler, C. K., Xiao, C. L., and Legard, D.E. 2000. Comparison of sanitation and fungicides for management of Botrytis fruit rot of strawberry. Plant Dis. 84:1197-1202.

Olaya, G., and Köller, W. 1999. Diversity of kresoxim-methyl sensitivities in baseline populations of Venturia inaequalis. Pest. Sci. 55:1083-1088.

Russell, P. E. 2002. Sensitivity baselines in fungicide resistance research and management. Pages 4-54 in: FRAC Monograph No. 3. Crop Life Int. Brussels, Belgium.

Smilanick, J. L., Mansour, M. F., Mlikota Gabler, F., Margosan, D. A., and Hashim-Buckey, J. 2010. Control of postharvest gray mold of table grapes in the San Joaquin Valley of California by fungicides applied during the growing season. Plant Dis. 94:250-257.

Sorensen, K. A., Gubler, W. D., Welch, N. C., and Osteen, C., eds. 1997. The importance of pesticides and other pest management practices in U.S. strawberry production. National Agricultural Pesticide Impact Assessment Program Document No. 1-CA-97, North Carolina Coop. Ext. Serv., Raleigh, NC.

Strand, L. L., ed. 2008. Integrated Pest Management for Strawberries, 2nd Ed. Pub. No. 3351. Dept. of Agric. and Nat. Resources, Univ. of California, Oakland, CA. 
UC IPM. 2008. Strawberry: Botrytis fruit rot. Pest Management Guidelines, Statewide Integrated Pest Manage. Program, Univ. of Calif., Davis.

Online: $\mathrm{http}: / / \mathrm{www} . i p m . u c d a v i s . e d u / \mathrm{PMG} / \mathrm{r} 734100111 . \mathrm{html}$

USDA-NASS. 2014. Statistics by subject. strawberry. acres harvested. price received. United States Department of Agriculture-National Agricultural Statistics Services, Washington, DC. Online: http://www.nass.usda.gov /Statistics by Subject/
Veloukas, T., Leroch, M., Hahn, M., and Karaoglanidis, G. S. 2011. Detection and molecular characterization of boscalid-resistant Botrytis cinerea isolates from strawberry. Plant Dis. 95:1302-1307.

Weber, R. W. 2011. Resistance of Botrytis cinerea to multiple fungicides in northern German small-fruit production. Plant Dis. 95:1263-1269.

Weber, R. W., and Hahn, M. 2011. A rapid and simple method for determining fungicide resistance in Botrytis. J. Plant Dis. Prot. 1:17-25. 